\title{
Children's Depression Rating Scale, Revised Clinical Classification
}

National Cancer Institute

\section{Source}

National Cancer Institute. Children's Depression Rating Scale, Revised Clinical

Classification. NCI Thesaurus. Code C155323.

A standardized 17-item clinician rating scale for the assessment of depressive symptomology in children and adolescents. The instrument, which is based on the adult Hamilton Depression Rating Scale developed by Max Hamilton at the University of Leeds in 1960, was published by Poznanski and Mokros in 1996 as a rating scale for children 6 12 years of age. In 2010, Mayes et al. demonstrated its use in adolescents. 